in malaria may give some indication of the extent to which the corpuscles of the patient have been subjected to an injurious influence and so give some indication of those cases of malaria in which it would be dangerous to give quinine. It is interesting to note in this connexion that if to a dog a quantity of toluene-diamin be administered insufficient to produce hæmoglobinuria, yet we have in these cases a raised isotonic point-i.e., a lowered resistance of blood cell (Lapicque et Vast ${ }^{15}$ ).

Another factor that is of some use as an index of danger is the presence of albuminuria or a high-coloured urine. The colour in these cases is not due to bile pigment, but may be due to urobilin.

To conclude, blackwater fever is essentially a malarial infection in which quinine is the most common immediate determining cause of intoxication. Protection from malaria will insure protection from blackwater fever. Complete protection from malaria may, as my own two years' experience in tropical Africa under all kinds of conditions shows, be attained without the taking of any quinine, by paying scrupulous attention to clotining and the nse of the mosquito net.

\section{THREE CASES OF ACUTE DIFFUSE SEPTIC PERITONITIS RESULTING FROM APPENDICITIS ; OPERATION ; RECOVERY.}

BY W. G. RIOHARDSON, M.B.DuRH., F.R.C.S. ENG., ASSISTANT SURGEON, ROYAI INFIRMARY, NEWCASTLE-ON-TYNE.

OASE 1.-A lad, aged 13 years, was on Jan. 6th, 1900, getting ready at 1.45 P.M. to go into Newcastle with his mother, when he felt a little pain in his abdomen, low down on the right side. He spoke of it at the time, but, thinking that it was ordinary stomach-ache, he put on his coat and caught the 2 o'clock train at Heaton. Whilst shopping in town the pain became steadily worse and he had to walk about holding on to his mother's arm. Eventually he could bear it no longer and he was taken to the station, where he sat waiting for a train to go home. His mother then noticed that he was very ill. On arriving at Heaton at 4 o'clock he became much worse and was doubled up with pain, and whilst walking with great difficulty up the inclined way ont of the station he vomited. After getting home he became feverish and was put to bed. At 10.45 be had a rigor and vomited again. At $1.30 \mathrm{~A} . \mathrm{M}$. on the 7 th he was seen by Dr. A. Livingston who prescribed for him, and he slept until 7 o'clock, when he woke up feeling rather better but in a burning heat and the pain was still there. At 10 o'clock he was seen by Dr. F. Russell who found him delirious. During the afternoon he again had a rigor and he vomited twice. Heat was applied to the abdomen and gave some relief, but he still wandered in his talk. When I saw him with Dr. Russell (at 10 P.M.) he looked very ill, with pinched features, high temperature, rapid pulse, and dry tongue. His abdomen was slightly distended, rigid, and extremely tender all over. Dr. Russell agreed with me that his condition was due to general peritonitis and that the only useful treatment was an operation. As there was neither accommodation nor preparation for such treatment in his home, the boy was wrapped $\mathrm{up}$ in the bedclothes in which be lay and was at once taken in a cab to a private hospital. At 1 A.M., on the 8 th-i.e., 35 hours from the onset of the illness-assisted by Dr. Russell, I operated by the method introduced by $\mathrm{Mr}$. J Rutherford Morison, making a long oblique incision from the onter edge of the right rectus abdominis npwards, ontwards, and backwards into the loin. The abdominal cavity was full of milky pus and, after the excess had poured ont of the wound, the appendix was found lying with its tip in the pelvis. There were no adhesions and the appendix was perforated. It was removed and the abdominal cavity was mopped out with gauze until all the pus appeared to bave been cleared away. Gauze wrung out of normal saline solution was then put in as a drain; one piece in the pelvis, one amongst the small intestines, and one up to the liver. All the loose ends

15 Comptes Rendus Hebdomadaires de la Société de Biologie, May, 1899 , p. 369 . of gauze were bronght ont together at the hinder end of the wound. The wound was then sewn up in layers witb catgut and a dressing was applied which was changed every four hours. The after history was uneventful and the boy is now perfectly well.

CASE 2.-A youth, aged 17 years, was at work on the morning of May 23rd, 1900, but he felt weary and complained of a little pain in the lower half of the abdomen. He went home and took his midday meal as usual and then lay down on a couch. Whilst so lying he felt a sudden acute pain in the abdomen, but did not vomit. His mother applied hot fomentations and gave him a dose of castor oil which acted freely, and he felt easier. (It appears that he had had two similar attacks-one two years before and the second a year afterwards-that both had been treated in the same way, and that each had passed off in a few hours.) He had a good night and in the morning he felt better, but he complained of ftelling "sore across his belly." $\mathrm{He}$ got up, dressed, and lay on the couch. At 1.30 P.M. he jumped up suddenly and screamed with a violent pain in the abdomen. He then turned faint and vomited. He was seen for the first time by Dr. W. L. Ruxton at 3 o'clock, and at 4 o'clock I saw him in consultation. He was then very il, with an anxious expression, a fast pulse, a slightly raised temperature, and a dry tongue. He ar peared to be in great pain and his abdomen was very tender, hard, and slightly distended. He was taken at once in a cab to a private hospital where I operated at 7 P.M.-i.e., about 30 hours after the acute onset of illness-by the same method as wa empleyed in Case 1 . There was such a large quantity of similar milky pus that I turned him on to his side and allowed the pus to run out. His appendix, which was perforated and non-adherent, was removed, the abdomen was mopped out with gauze, and three gauze drains were left in-owe under the liver, one in the pelvis, and one amongst the coils of small intestine-the ends of all emerging from the hinder end of the flank incision. During the two following days the patient was very ill and the abdomen became gradually distended with flatus. On the morning of the $27 \mathrm{th}$ he became unconscious, and I thought that he was dying. No tlatus had passed for 48 hours. The tongue was dry, the teeth were covered with sordes, ard the pulse was becoming weaker and steadily quicker. As no flatus came through an ordinary rectal tube I passed a Kelly's long sigmoid speculum, and a little flatus and watery fæces came away. By repeating this many times I got away what in the aggregate amounted to a large evacuation. The tube was passed every balf-hour during the morning and afternoon, when, to my surprise, the pulse began to tall and the patient improved slowly through the night. He regained conscionsness, made an excellent recovtry, and is now in perfect health. I had never previously seen anyone who was so ill with acute septic general peritonitis recover.

OASE 3.-A married woman, aged 35 years, was cn Nov. 13th, 1900, shopping all day in a town 10 miles distant from her home. On her return in the evening she did not feel well, and during the night she woke out of her sleep with great pain all over her abdomen. Having had similar attacks, which she had been told were due to appendicitis, on two previous occasions-the first in June, 1899, and the secrnd six months later, during each of which she was laid up in bed for a few days-she thought that this illness arose from the same cause, and she sent for Dr. F. Hunton, of Sedgefield, who saw her on the morning of the 14th. Dr. Hunton found her with raised temperature, fast pulse, rigid but not distended abdomen, and marked tenderness in the right iliac region. During the morning she vomited. A purgative was administered and hot fomentations were applied. She continued to ftel ill during the whole of the 14th, but the pain subsided somewhat towards night. Her bowels were moved and she vomited during the evening. At 1 A.M. on the $15 \mathrm{th}-\mathrm{i} . \mathrm{e}$., nearly 24 hours after the initial attack - she was suddenly seized with excruciating pain in the abdomen, vomited immediately, and became very ill and collapsed. Farly in the morning, when seen by Dr. Hunton, she was much worse than on the previous day. Morphia gave some relief. Farly in the afternoon she was again seen and it was then noticed that her abdomen was beginning to swell. At 7 P.M. I saw her with Dr. Hunton. She was then looking very ill; she bad pinched features, a dry tongue, and a feeble voice. Her pulse was rapid and hard. Her abdomen was moderately distended and the right iliac region was excessively tender, so much so that $I$ could not make ont whether or not there 
was a lump It was clear, however, that she was suffering from acute peritonitis, that her intestines were beginning to distend, and that if she could not be relieved she was likely to die. Believing that the source of the peritonitis was a rupture of the appendix we decided to operate at once, which I did by the same method as in Case 1 and Case 2. The appendix was found to be perforated and there was a great quantity of thin and milky pus amongst the small intestines, in the pelvis, and up under the liver. I removed the appendix, mopped up the pus with gauze until the peritoneum appeared to be clean, and then placed one gauze drain in the pelvis, another under the liver, and a third amongst the small intestines, bringing them all out at the after end of the flank incision. The following morning the temperature was $99^{\circ} \mathrm{F}$., and the pulse was 100 and of good character. Slight sickness and hiccough, with some abdominal distension, were present. The gauze was removed on the fifth day. The patient made a good recovery and is now in excellent health.

These three cases are strikingly similar and are typical of the "fulminating" form of acute appendicitis which is the most fatal of all varieties. In the initial stages they were not distinguishable from ordinary cases of appendicitis in which recovery could take place either by resolution of the inflammatory prosess or by limitation of the disease to the formation of an abscess ; yet in the more advanced stage, and without warning, the life of each patient was placed in immedia'e danger and death could only ba averted by immediate operation, performed with the minimum amount of preparation which could be desired. In each of these cases there was a premonitory stage, lastiog for a few hours, during which the patient felt unwell and uneasy in the abdomen. This was followed by the sudden development of acute symptoms which subsided somewhat after several hours of severe pain. This lull was followed in about 24 hours from the initial acute attack by strikingly violent and sudden increase of all symptoms and in seven or eight hours more the abdomen was found to be full of pus. In each case the appendix was seen at the operation to be acutely inflamed without any surrounding adhesions and to have a gangrenous perforation through its walls

The interpretation which I put on these symptoms is as follows. The appendix being strictured, or an enterolith becoming impacted fluid collected and distended the appendix, causing uneasiness-appendicular colic. This, I believe, might pass away and give no further trouble, but the tension in the appendix increased and then the pain, owing to the stretching of the peritoneal coat, became very great-the initial attack. The contents being septic, and no relief of tension having taken place, the appendix became acutely inflamed and the pain was aggravated-the period of local pain and of feverish symptoms. As the inflammatory process advanced the walls of the appendix gradually sof tened and lost their power of keeping ap tension-the lull, during which the patient felt less pain, in fact, was " rather better." The relief was similar to that experienced when an inflimed lymphatic gland goes on to suppuration, for in sush a case the pain becomes less when the causule of the gland softens and stretches. After this period of relieved tension the peritoneal coat of the appendix gave way at one or more pjints, possibly where the gangrenous process bad been accelerated by the pressure of an enterolith. and the sep ic contents escaped-the acute exacerbation of pain and vomiting. The entire process was so rapid that no adhesions bad time to form, and from this stage onwarls the symptoms of acate appendicitis became lost in the $m u$ ih graver symptoms of acute general septis peritonitis.

If, as I believe, the above is a true picture of the pathological process as revealed by the symptoms in these "fulminating" cases, then it may be possible to formulate some rule which will enable us to recognise them and to operate before such a catastrophe as general septic peritonitis supervenes; for the process differs only from the course of events in ordinary cases, which terminate by resolution or in the formation of an abscess, in the virulence and rapidity of the process and in such changes as are due to that rapidity. Toe difference is one of degree but not of kind. I do not wish to advocate operating in all cases of acnte appendicitis; on the contrary, I believe that it is a fact, which is borne out by the experience of every medical man who is engaged in general practice to whom I have spoken that for one case which requires operative treatment there are many which do well without operation. Not only many medical men but nearly every layman has been shocked by the death of some patient or acquaintance from peritonitis within two or three days of his being seen in perfect health. These cases are almost without exception examples of peritonitis following fulminating appendicitis ; and although they represent only a small percentage of the total number of cases of appendicitis they actually amount to a great number. On Nov. 16th, 1900, I saw a man, aged 38 years, with the following history: He was at work all day on the 14th. During the evening, being then in his usual health, he went to the water-closet, but returned to the house looking ill and complaining of pain in his abdomen. The pain continued all night and he vomited. He was ill all the next day. Early in the morning of the 16 th the pain became much worse and he vomited; he looked very ill and his abdomen commenced to swell. At 6.15 P.M. I saw him in consultation. He was lying on his right side with his legs drawn up. His abdomen was greatly distended and was dull in the right half ; it was very tender, especially in the right iliac region, where there was a lump as big as a fist-so tender that the man cried out when it was touched although he was then dying. His medical man told me that this was the third similar case in his practice in a fortnight where the patients had died and all of them had died within 48 hours of the onset of symptoms.

In cases where adhesions are formed and an abscess develops there is not the same immediate necessity for operation as in these acute cases, where prompt action must be taken because a very few hours' delay may result in the death of the patient; therefore it is of the utmost importance to be able to recognise these urgent cases before perforation of the appendix occurs. The rule which $I$ follow is this. If the patient is seen within a few hours of the onset of the illness hot fomentations are applied to the abdomen. Morphia is only given in cases of urgent need. I then wait and see what progress is made. If there is steady improvement waiting is persevered in as long as this continues. By "improvement" I mean improvement in all the symptoms. It is not enough that pain and tenderness should be less, for the period during which the pain diminishes may be the very time in which an operation should be performed. All the symptoms should subside together: the temperature should fall, the pulse should become less frequent, local pain and tenderness should grow less, and the patient should look better. The last is an uscertain quantity but a very important one. The chief points are a diminution of the local tenderness and lessened rigidity of the muscles, but these must not be taken as a certain guide when the patient continues to be otherwise ill. In illustration of this I may mention a case which I saw on May 2nd, 1899, with Dr. George R. Murray and Dr. W. T. Hall, at Whitburn. The patient was a little girl suffering from a first attack which began the day before. The local pain and tenderness had much improved, but the child still looked flushed and ill, and had a foul tongue and raised pulse and temperature. We decided to operate at once because we thought that the greater risk lay in leaving her alone. The appendix was found to be lying across the pelvis with its tip near the brim of the left side. There were no adhesions whatever, and the peritoneal coat of the appendix was bright scarlet, whilst, on opening it, the mucous and muscular coats were seen to be completely gangyenous. We all felt sure that this was a case in which general peritonitis would have followed sloughing of the entire appendix, as the inflammatory process was advancing so rapidly that there was no reasonab'e pr sspect of localisation by adhesions. This child-assuming my previous explanation to be the correct one-was operated on during the period of ease in which the peritoneal coat of the appenaix had softened and relaxed sufficiently to reduce the tension and with it the local pain and tenderness, but the improvement in local symptoms was no indication of subsidence of the disease.

If such a rule be followed-namely, to remove the appendix in very acute cases which at the end of 24 hours do not improve in all the symptoms-a large number of lives will be saved which are often, perhaps usually, lost through the operation being performed after perforation has taken place. At the same time, it is obvious that by applying such a rule a number of cases will be operated on in which, although the appendjx is on the point of giving way, it is yet guarded by adhesions. Against this must be placed the risk of waiting and the possibility of abscess formation, and above all the simplicity and safety of operating at this stage must be taken into account. This, however, must not be made an excuse for a 
hard and fast rule of treatment that all cases of acute appendicitis must be operated on. Surely that is not sound surgery. If the appendix has perforated and general peritonitis has become established it is then a maiter of supreme importance to operate without any unnecessary delay - unless the abdomen is distended with flatulent intestines or the hands are cold and red, when it is best not to operate at all, as there is evident general vascular and nerve failure and any operation could only hasten death.

In the first few hours of acute general peritonitis the distension $i / 3$ not due to gas in the intestines, but to a collection of thin milky-looking pus in the general peritoneal cavity; whereas in the later stages there is little or no fluid and the distension is due to gas in the intestines, which are then dark-coloured, dry, and sticky, with adherent lymph on the peritoneal surfaces, suggesting that the wall of the intestine has played the part of a sieve, allowing the fluid to pass through but retaining the solid portion of the pus as a covering of ly mph.

The method of draining the peritoneal cavity with gauze appears to me to be preferable to that by drainage through a tube. When the coils of the intestines are lying in close apposition it does not seem to be a hopeful way to drain with a tube which can only be efficient for a limited area. It seems difficult to drain the pelvis against gravity by means of a tube which can on'y do good by relieving tension and allowing the pus to empty freely trom the upper end. On the other band, by using gauze drains packed loosely amongst the intestines a very large area of the peritoneal cavicy can be drained, and more than drained, for the gauze acts as a suction pump and will for dass continue to empty the peritoneal cavity as a wick will empty a bottle. It is not a painful operation to withdraw such gavze if it be left in for five days. The attempt to do this on the second or third day gives great pain, but later the meshes of the gauze are filled up by lymph which makes its surface smooth and slippery and its removal easy.

Newcastle-on-Tyne.

\section{RESECTION OF THE SUPERIOR CERVICAL GANGLION OF THE SYMPATHETIC FOR GLAUCOMA} AND ITS RESULTS.

BY H. WORK DODD, F.R.C.S. ENG.,

OPHTHALMIC SURGEON TO, AND GLINICAT LECTURER ON OPHTHALMIC MEDICINE AND SURGERY AT, THE ROYAL FREE HOSPYTAL; BURGEON TO THE ROYAL WESTMINSTER OPHTHALMIO HOSPITAL, ETC.

IT may be seen on reference to a contribution by me on this operation which appeared in THE LAXCET of Oct. 13th, 1900 , p. 1071 , in which I described my first case, how I there advanced the opinion that "if such an operation does permanently and satisfactorily arrest the glaucoma, preserve the sight, relieve the pains, and restore the patient to even comparative comfort, then I consider it may be undertaken.", I may at once say that the later results of this, my first case, as also those of $\mathrm{my}$ second case, which $\mathrm{I}$ here briefly describe, are not so favourable as to lead me to regard the removal of the superior cervical ganglion of the sympathetic as successful in the cure of chronic glaucoma. It may, perhaps, be repeated here that these operations were basfd upon the work of Dr. Jonnesco of Bucharest.

My second case was that of a fairly well-nourished country woman, aged 44 years, unmarried. She was admitted into the Royal Free Hospital under my care on Oct. 16th, 1900, suffering from chronic glaucoma in both eyes. The disease commenced about two years before this date, when she began to have pain in the left eye which was operated upon in January, 1900. After the operation the eye was better for a while, but gave trouble again about three months later, and at this time the right eye also became painful. Both eyes were operated on in June, 1900, and the Jeft one again in the following September. The pain and other symptoms not having lessened since this last operation, Dr. E. E. Maddox of Bournemouth, under whose excellent care she had been, thinking her a suitable subject for the bilateral removal of the superior cervical ganglions of the sympathetic, kindly sent her up to me for this operation, he having been interested in my previous case. When 20 years of age, that is about 24 years ago, the patient bad cataracts removed from both eyes. Her general bealth bad always been good.

On admission, in the right eje there was a large coloboma from iridectomy in the upper part of the iris wbich otherwise appeared to be fairly normal and fuee. There was no lens and the edge of the remaining capsule could be seen. The tension was about +2 . The field of vision was considerably and irregularly contracted. The disc was cupped and the fundus showed other signs of chronic glaucoma. The vision $=\frac{1}{60} \overrightarrow{\mathrm{c}}+11 \mathrm{D}=\frac{6}{18}$. The patient complained of constant pain, varying in intensity, in the eye and head. In the left eye there was a large operative coloboma upwards, the iris being otherwise practically normal. The lens was absent and the pupil area showed some remains of capsule: There was also a very little pericorneal injection. The tension was about +3 . The vision was reduced to perception of light only. The disc was cupped and there were other indications of glauccma in the fundus. The fatient had a corsiderable amount of pain, more or less constant, in this eye, which also was somewhat tender.

In my former case I removed the two superior cervical ganglions at one sitting, but I found this to be a somewhat heavy and trying experience for the patient. Wishing also to notice the effect of the unilateral operation I determined in this case to remore the ganglions at different times. Accordingly, on Oct. 19th I removed the superior cervical garglion of the left side. The operation chosen was that described by Dr. Jonnesco under the name of "pre mastoid" which has been previously fully reported in my communication alluded to abcve and therefore need not be repeated bere. Immediately after the resection of the left ganglion the tension of the eye became a soft normal. On the next morning there was slight ptosis, the eyeball appeared to be a little sunken in the orbit, and the tension remained a soft normal. There was also a little injection of the conjunctiva. On the 22nd the tension was still low. There was some alteration in the voice. which sounced somewhat groffer than usual, and it hurt the patient to talk. She protruded her tongue with difficulty. There was no excessive amount of mucus in the pbarynx. She did not complain of any pain in the neck or bead on that side. These had been no pain in the eye since the operation. On the 26 th the wound was practically healed and the patient sat up for a short time. On Nov. 1st the patient felt very well, , the wound was quite healed, and there was no pain in the eye. The tension remained soft. On the 5 th the same operation was repeated on the right side of the neck, with like results as to 1 ension, ptosis, \&c. The stitches were removed on the $12 \mathrm{th}$, and on the $15 \mathrm{th}$ the wcund was quite healed, the case having done uninterruptedly well since the operation. On this day there was no pain in the right eye and the tension was a scft normal. On the 16th the patient complaincd of some pain over the right eje during the previous night. 'I be tersion in the right eye was normal, but that in the left eye gave a faint suspicion of being slightly raised. On the 19 th the tension was normal in both eyes. There was no pain in either eye nor in the head. The ptosis had practically disappeared. The field of vision of the right eje was considerably increased, and the vision itself had improved from $\frac{1}{60}$ to $\frac{6}{6}{ }^{\frac{6}{0}}$ without glasses, $\bar{c}+11 \mathrm{D} s \mathrm{ph} .=\frac{6}{18}$. The patitnt was discharged on the next day.

The method of operating at intervals on the two sides of the neck appears to be a mcre satisfactory procedure than that of removing the two ganglions at one time.

Dr. Maddox, about Christmas time, kindly reported by letter that the tension had returned and that he found it necessary to employ pilocarpine drops. On Feb. 18th, 1901, Dr. Maddox wrote to say that the tension was then +2 . The eyes then bave returned to the same state as they were in before the operations for the removal of the ganglions were performed. Therefore, though in this case the immediate effects were extremely favourable for a few days, the permanent result of the operation $s$ for the cure of the glaucoma is nil. Inasmuch as this patient had no lenses sbe was thought to be a suitable subject for this operation. The possibility of the glancoma resulting from cicatricial changes was naturally also considered.

$I$ also bere give the final results of my former case. ${ }^{1}$ It can be seen on reference to the details that in that case also the immediate effects were distinctly satisfactory. It is 